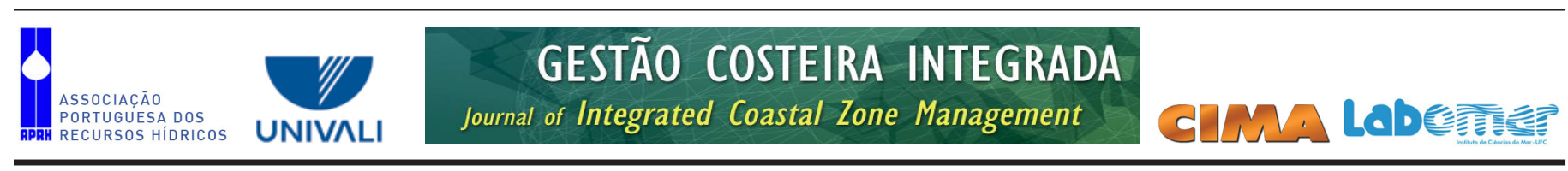

http://www.aprh.pt/rgci/pdf/rgci-432_Mello.pdf | DOI:10.5894/rgci432

\title{
Dinâmica da expansão urbana na zona costeira brasileira: o caso do município de São Vicente, São Paulo, Brasil *
}

\author{
Urban expansion dynamic in the Brazilian coastal zone: \\ the case of São Vicente city, state of São Paulo, Brazil
}

\author{
Kaline Mello ${ }^{\circledR, 1}$, Rogério Hartung Toppa ${ }^{2}$, Denis Moledo de Souza Abessa ${ }^{3}$, Mariana Castro ${ }^{2}$
}

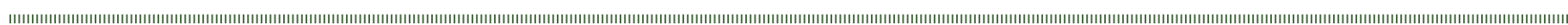

\section{RESUMO}

A região costeira do Estado de São Paulo passa por constante processo de expansão urbana, de forma, geralmente, não planejada, resultando na supressão de áreas naturais, principalmente os ambientes costeiros sensíveis, como manguezais, restingas e encostas. Em especial, a Região Metropolitana da Baixada Santista (RMBS), localizada no centro do litoral do Estado de São Paulo, sofre pressão urbana ligada à expansão das atividades econômicas na regiáo. Nesse sentido, o presente trabalho analisou a dinâmica da expansão urbana do município de Sáo Vicente, localizado na RMBS, entre os anos de 1963 a 2007, correlacionando-a com os ciclos econômicos e as políticas públicas regionais, com o objetivo de subsidiar o planejamento territorial e ambiental das cidades litorâneas. Para tanto, foram utilizados seis mosaicos de fotografias aéreas de cada década analisada, para o mapeamento das áreas urbanas em ambiente SIG. Os dados sobre a urbanizaçáo foram cruzados entre os anos para se obter a expansão urbana no período analisado. $\mathrm{O}$ maior crescimento das áreas urbanas $(29,75 \%)$ foi observado no período de 1972 a 1987, intimamente ligado ao incremento de infraestrutura na regiáo, em especial com a expansão das rodovias que ligam a capital do estado com a Baixada Santista. A área insular de São Vicente já se apresentava bastante consolidada em 1963, com expansão de núcleos urbanos ao longo do período analisado associado ao processo de favelizaçáo. A expansão urbana foi maior na área continental do que na área insular, tendo as estradas e ferrovia como vetores de ocupação. O crescimento econômico da Baixada Santista, relacionado à exploração de óleo e gás na Bacia de Santos e à expansão das atividades portuárias, poderá direcionar ainda mais o adensamento urbano para São Vicente, ameaçando os remanescentes de Mata Atlântica das Unidades de Conservação da regiâo. O processo histórico de ocupação identificado indica uma tendência regional de drástica substituiçâoo da paisagem natural ainda existente em áreas limítrofes às Unidades de Conservaçáo, por uma paisagem antrópica, que, provavelmente, será representada por ocupaçôes irregulares sem infraestrutura urbana adequada para a sustentabilidade regional.

PALAVRAS-CHAVE: Baixada Santista; Mata Atlântica; Serra do Mar; Sistema de Informaçôes Geográficas, Planejamento Ambiental.

@ - Corresponding author: <kaline.mello@gmail.com>

1 - Universidade de São Paulo, Escola Superior de Agricultura "Luiz de Queiroz", Departamento de Engenharia de Biossistemas. Avenida Pádua Dias, 11, Piracicaba, SP, Brasil.

2 - Universidade Federal de São Carlos, Campus de Sorocaba, Departamento de Ciências Ambientais. Rodovia João Leme dos Santos, km 110, Sorocaba, SP, Brasil.

3 - Universidade Estadual Paulista "Júlio de Mesquita Filho", Campus Experimental do Litoral Paulista. Praça Infante Dom Henrique, s/n", São Vicente, SP, Brasil. 


\section{ABSTRACT}

The Coastal Zone of São Paulo State (Southeast Brazil) has been under a constant process of urban expansion, which usually occurred by an unplanned way, resulting in the suppression of natural areas, especially some sensitive coastal environments such as mangroves, salt marshes and Atlantic rainforest formerly occupying hillsides and lowlands. In this sense, this study analyzed the dynamic of urban growth of Säo Vicente city, located on the central-south coast of Säo Paulo, between the years 1963 to 2007, with main concern for the urban expansion in the Coastal Zone. To achieve that, we used six mosaics of aerial photographs from each decade within the analyzed period, in order to $r$ map the urban areas in a GIS environment. Data on urbanization were crossed between the subsequent decades to get the urban expansion in the analyzed period. We correlated the urban expansion cycles with regional public policies, with the aim of subsidize the comprehension of the territorial and environmental planning of coastal cities. The largest growth in urban areas (29.75\%) was observed in the period 1972 to 1987, and was closely linked to the establishment of anthropic infra-structure (railways, roads, pipelines, electric transmission lines, among others) in the region, particularly the expansion of highways linking the state capital with the coastal cities (especially Santos, Cubatão, São Vicente, Guaruja). This period is coincident to the larger population growth within the studied timeline, when more than 76,000 inhabitants established in the city. The occupation of the island of São Vicente has already had quite consolidated in 1963, and the further expansion of urban centers during the analyzed period was associated with the process of slumming. Urban expansion was greater in the continental area, reaching to 200\%, where roads and railways represented the main vectors of occupation. Territorial occupation was also influenced by the high valuation of terrains situated close to the beaches and the concentration of real state ventures, which were mostly reserved to serve as second residences for richer people, whereas poorer classes were induced to occupy mangroves, estuarine banks and hillside areas, most of them within protected or vulnerable areas. A strong correlation was observed between occupied are and population growth rates, showing that migration and arrival of new inhabitants were associated to loss of natural areas. However, the occupation speed seemed to be regulated by macroeconomic factors, in addition to the expansion of roads. The rates of population and urban growth during the last two periods were reduced in comparison to the initial periods; however, it must be highlighted that both population and urbanization presented a continuous growth, which was initially more intense. Another important factor that historically have exerted pressure on the natural areas of Säo Vicente is the seasonality, as fluctuating population reaches to more than 1,350 thousand people, which is almost equivalent to the resident population. The recent economic growth of Santos, related to oil and gas exploration in the Santos Basin and the expansion of port and industrial activities, may induce further urbanization for São Vicente, threatening mangroves and the remnants of Atlantic Forest from the local Protected Areas, as well as their nearby areas, which have the function of being buffer zones. Urban sprawl in coastal zones should attend the various planning instruments that are applied to rule territorial ordering and solve land use conflicts, considering the protection of natural environments from economic interests, as predicted by the Federal and State coastal management plans.

Keywords: Baixada Santista; Atlantic Rain Forest; Serra do Mar; Geographic Information System; Environmental Planning.

\section{INTRODUÇÁO}

A zona costeira é reconhecida por apresentar usos múltiplos dos espaços e dos recursos naturais, com diferentes formas de ocupação e desenvolvimento de diversas atividades humanas. A Região Metropolitana da Baixada Santista (RMBS), localizada na porção central do litoral paulista, caracteriza-se especialmente por ser uma regiáo altamente urbanizada e populosa, reflexo do crescimento econômico ligado às atividades industriais e portuárias e ao turismo de veraneio (Afonso, 2005). Criada formalmente em 1996, a RMBS é formada por 9 municípios: Bertioga, Cubatão, Itanhaém, Mongaguá, Peruíbe, Praia Grande, Santos e São Vicente e possui o maior porto da América Latina. Limitada pelas escarpas da Serra do Mar, a RMBS engloba uma faixa estreita de planície litorânea, com intensa urbanizaçáo principalmente nas cidades de São Vicente, Santos, Cubatão e Guarujá. A falta de planejamento do crescimento urbano, somada ao crescimento econômico e industrial, constituiu o principal meio de alteração da paisagem na região (Afonso, 2006).

Entre 2007 e 2009, a RMBS foi a região paulista de maior crescimento populacional, e os novos investimentos em toda a zona costeira, desde a ampliação do corredor de exportaçôes de São Sebastião até descobertas de óleo na Bacia de Santos (nas áreas conhecidas como pré e pós-sal), poderão resultar num aumento das migraçóes devido à expectativa de geração de empregos (SMA/CPLA, 2009). A RMBS é o principal polo centralizador das indústrias que pretendem atuar, direta e indiretamente, na exploração de óleo e gás em águas rasas e na região do Pré-Sal, favorecendo o desenvolvimento econômico da regiáo, podendo contribuir para o aumento populacional e agravar os casos de ocupação irregular. Considerando que a regiâo dispóe de quantidades limitadas de áreas para a expansão urbana, existe a forte preocupação de que ocorra aumento de ocupaçôes em áreas protegidas, como manguezais ou o Parque Estadual da Serra do Mar (PESM), que protege toda a escarpa desde o limite sul até o limite norte do litoral paulista (SMA/CPLA, 2009).

O município de São Vicente ilustra o conflito entre os usos múltiplos na zona costeira, sendo o segundo município mais populoso da RMBS, que enfrenta problemas com o crescimento urbano desordenado e a especulação imobiliária, intensificando a ocupação de áreas ambientalmente frágeis e de risco. Por outro lado apresenta uma importância ecológica muito grande, com $65 \%$ de sua vegetação considerada sob algum tipo de proteção legal (SMA/IF, 2007), principalmente pela presença de Unidades de Conservação (UC), como o PESM e o Parque Estadual Xixová Japuí (PEXJ). O PESM é a maior UC do Estado de São Paulo, e um dos maiores remanescentes do bioma Mata Atlântica. O planejamento territorial e ambiental das cidades litorâneas, como é o caso de São Vicente, deve ser realizado de forma a evitar a ocupação 
irregular em regióes, o que além de provocar impactos negativos sobre a biodiversidade, promove a alteração da topografia e da permeabilidade do solo, o que pode causar riscos à saúde humana (Afonso, 2006).

As análises das mudanças no uso e na cobertura da terra representam uma abordagem para avaliar as mudanças nos ecossistemas e suas implicaçóes ambientais em várias escalas temporais e espaciais (Lambin, 1997). Os Sistemas de Informação Geográfica (SIG) permitem a integração de dados espaciais de diferentes fontes e datas, transformando dados em informaçáo destinada ao apoio à decisão, subsidiando diagnósticos ambientais, elaboração de zoneamentos e previsão de cenários futuros (Toppa et al, 2013), podendo gerar projeçóes de alteraçóes ou impactos sobre os ecossistemas costeiros, visando à adoção de medidas mitigadoras quanto aos novos projetos e empreendimentos com vistas ao gerenciamento costeiro integrado (DahdouhGuebas, 2002). Permitem, também, estabelecer açôes e/ ou políticas que visem direcionar a urbanização para áreas consideradas mais adequadas, ao mesmo tempo em que inibam a ocupação das áreas ambientalmente sensíveis ou ecologicamente importantes.

Considerando o histórico de ocupaçáo desordenada e a tendência de aumento da pressão urbana na RMBS motivada pela exploração de óleo e gás e pela especulação imobiliária, assim como grande parte das cidades costeiras no Brasil e no mundo, foi analisada a dinâmica da urbanização do município de São Vicente no período de 1963 a 2007, associando dados de uso e ocupação da terra com dados dos ciclos econômicos e políticas públicas regionais, com a finalidade de subsidiar o planejamento urbano e territorial das cidades litorâneas.

\section{MATERIAL E MÉTODOS}

\section{1. Área de Estudo}

O município de São Vicente localiza-se entre as coordenadas UTM 7343485 - 7356739 N e 332094 $362510 \mathrm{E}$, na região central do litoral paulista e a $71 \mathrm{~km}$ da capital Sáo Paulo. Encontra-se no domínio Planalto Atlântico, com predomínio de planície costeira e escarpas da Serra do Mar (Figura 1), chegando até $1.000 \mathrm{~m}$ de altitude (Figura 2) (Amorim \& Oliveira, 2008) e vegetação do Bioma Mata Atlântica, com fisionomias de restinga, mangue e floresta ombrófila densa. Apresenta como limites os municípios de Itanhaém e Mongaguá ao extremo oeste, São Paulo ao noroeste, São Bernardo do Campo e Cubatão ao norte, Santos ao nordeste-leste, ao sul o Oceano Atlântico e ao sul-sudeste Praia Grande. A Ilha de São Vicente abriga parte dos municípios de São Vicente e Santos, e concentra o aglomerado urbano de ambas as cidades. A porção terrestre de São Vicente é representada por 13,4\% de área insular e por $86,6 \%$ de área continental. Por outro lado, a parte insular abriga $70 \%$ da população atual do município (IBGE, 2011), enquanto a área continental abriga as duas UC.

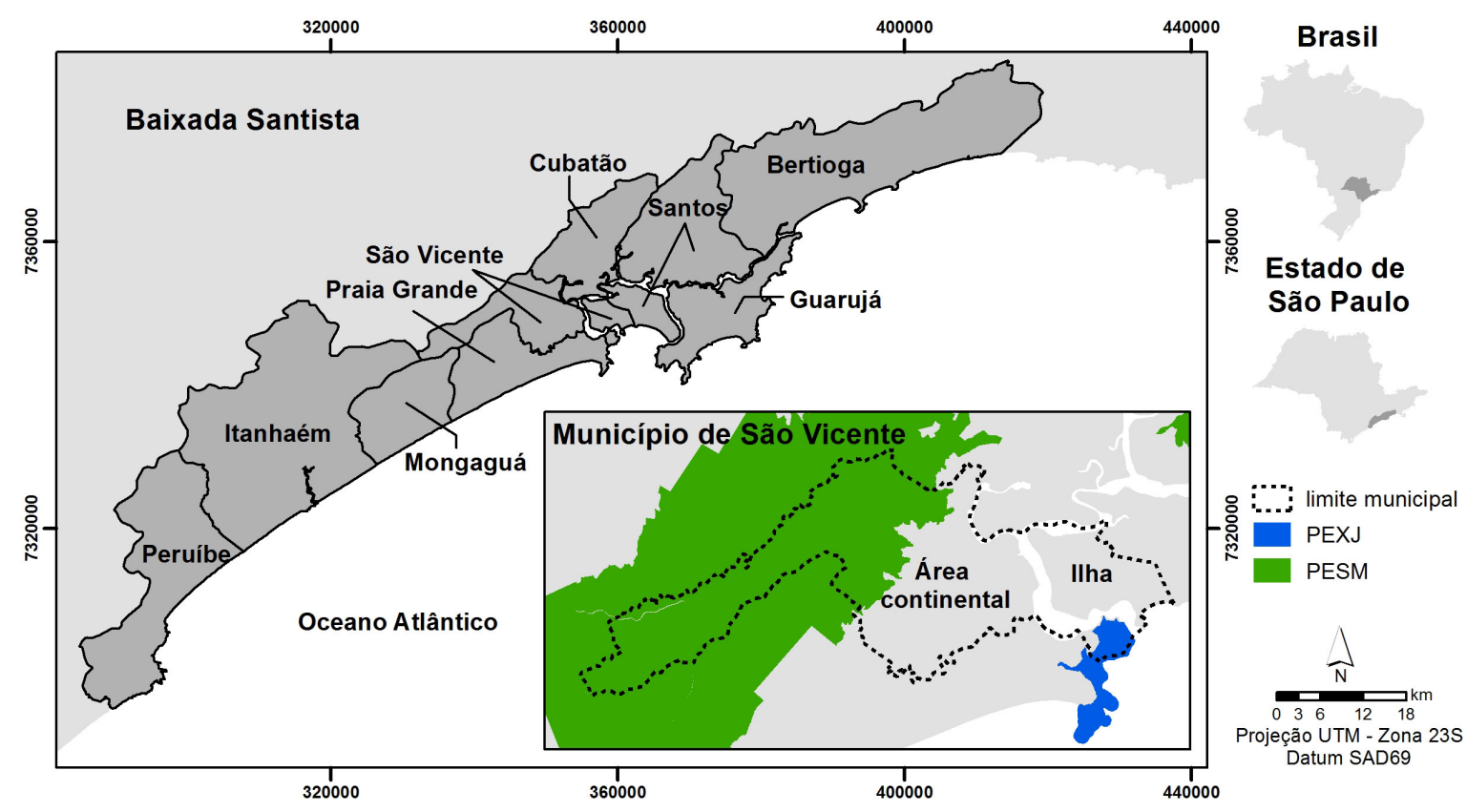

Figura 1. Localização do município de São Vicente, Baixada Santista, Estado de São Paulo, Brasil.

Figure 1. City of São Vicente, Baixada Santista, State of São Paulo, Brazil. 


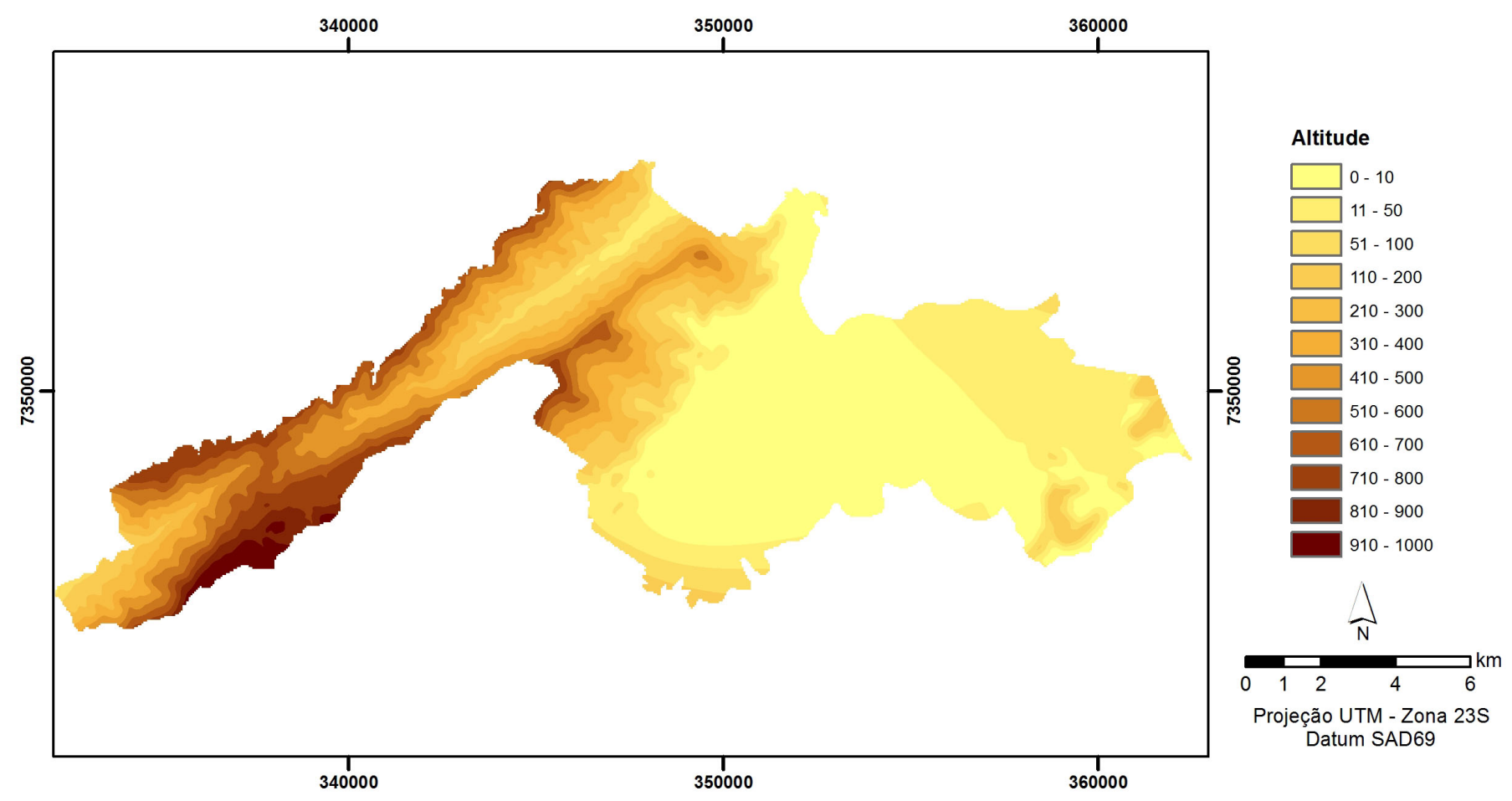

Figura 2. Mapa de altimetria do município de São Vicente, São Paulo, Brasil.

Figure 2. Elevation map of São Vicente city, State of São Paulo, Brazil.

\subsection{Procedimentos}

Para a análise espaço-temporal da expansão da urbanização no município de São Vicente foi utilizada uma série de fotografias aéreas ortogonais dos anos de 1963 (escala 1:60.000), 1972 (escala 1:25.000), 1982 (escala 1:35.000), 1994 (escala 1:25.000), 2001 (escala 1:25.000) e 2007 (escala 1:25.000). As ortofotos de 2001 e 2007 foram obtidas em formato digital, cedidas pela Polícia Ambiental Estadual. As fotografias de 1963, 1972, 1982 e 1994 foram digitalizadas, mosaicadas e georreferenciadas com a utilização do programa MapInfo 9.0. Foram feitas correções quanto a cor e descarte de bordas. Os pontos de controle para o georreferenciamento foram tomados do mosaico do ano de 2001.

O mapeamento das áreas urbanizadas, estradas e ferrovias foi realizado no programa MapInfo 9.0 pelo método de vetorização digital em tela por meio de interpretação visual, em escala 1:20.000. Após o mapeamento, foi verificada a verdade terrestre com o apoio de receptor GPS e máquina fotográfica digital, o que possibilitou a aquisição de novos dados, que, juntamente com as observaçóes de campo, levaram à confirmação das classes previamente interpretadas e ao acréscimo de novas informaçôes ao mapeamento.

Com o auxílio do MapInfo 9.0, foram calculadas as áreas em hectare de cada mancha urbana e a área total urbana para os seis mapas referentes aos diferentes anos, permitindo a obtenção das seguintes informaçóes:

- Quantificação das áreas urbanizadas, em hectares, para cada ano;
- Porcentagem da área urbanizada em relação ao total da área de estudo para cada ano;

- Tabulação cruzada das áreas urbanizadas em diferentes datas, quantificando respectivas porcentagens de variação para os períodos 1963-1972, 1972-1987, 1987-1994, 1994-2001 e 2001-2007.

A diferença de área em hectares de uma data para outra foi calculada para verificar o aumento ou a diminuiçáo da ocupação (equação 1).

$$
\text { Diferença }(\text { ha })=\text { Area }_{\text {datafinal }}-\text { Area }{ }_{\text {data inicial }}
$$

A porcentagem de variação para cada período foi calculada com base na equação 2 :

$$
\operatorname{Variaçāo~}(\%)=\frac{\text { Área }_{\text {datafinal }}-\text { Área }_{\text {data inicial }} \times 100}{\text { Área }_{\text {inicial }}}
$$

Para relacionar a dinâmica da urbanização com os ciclos econômicos e as políticas públicas adotadas nos períodos analisados, foi efetuado um levantamento bibliográfico do histórico da ocupação na região, bem como de dados censitários do município de São Vicente para todo o período de 1960 a 2010. Os valores de número de habitantes e área urbanizada foram comparados por meio de regressão linear. 


\section{RESULTADOS E DISCUSSÁO}

São Vicente apresentou um incremento de áreas urbanizadas de aproximadamente $95 \%$ entre os anos de 1963 e 2007 (Tabela 1), com pico de crescimento de 29,75\% no período de 72-87 (Tabela 2). O crescimento urbano e o crescimento populacional apresentaram alto valor de correlaçáo (88\%) (Figura 3), indicando que o crescimento das áreas urbanas está intimamente ligado à chegada de pessoas na região.
A área insular de São Vicente já aparece bastante ocupada no ano de 1963, e a partir de 1972 tem pouco crescimento urbano, com incremento de 305 hectares até o ano de 2007 (Figura 4; Tabela 1). Esse crescimento está associado à ocupação de alguns vazios urbanos na ilha, aterramentos de mangue e estuário e estabelecimento de palafitas, na maior parte ocupaçôes irregulares, uma vez que não havia praticamente mais áreas regulares a serem ocupadas a partir de 1972.

Tabela 1. População residente e total de área urbanizada no município de São Vicente/SP entre 1960 e 2010. * Fonte: IBGE, Censos Demográficos de 1960, 1970, 1980, 1991, 2000 e 2010.

Table 1. Resident population and total urbanized area in the city of São Vicente, State of São Paulo, between 1960 and 2010.

\begin{tabular}{|c|c|c|c|c|c|}
\hline Ano & $\begin{array}{c}\text { Populaçáo } \\
\text { (n }^{\text {o habitantes)* }}\end{array}$ & Área urbanizada (ha) & $\begin{array}{c}\text { Porcentagem de área } \\
\text { urbanizada (\%) }\end{array}$ & $\begin{array}{c}\text { Área urbanizada na } \\
\text { porção continental } \\
\text { (ha) }\end{array}$ & $\begin{array}{l}\text { Área urbanizada na } \\
\text { porçáo insular (ha) }\end{array}$ \\
\hline 1963 & 77.208 & 1.385 & 9,17 & 162 & 1183 \\
\hline 1972 & 116.485 & 1.765 & 11,69 & 327 & 1438 \\
\hline 1987 & 193.008 & 2.290 & 15,16 & 603 & 1687 \\
\hline 1994 & 268.618 & 2.484 & 16,45 & 799 & 1685 \\
\hline 2001 & 303.551 & 2.514 & 16,65 & 830 & 1684 \\
\hline 2007 & 332.445 & 2.686 & 17,9 & 943 & 1743 \\
\hline
\end{tabular}

* Source: IBGE, Demographic Censuses of the years 1960, 1970, 1980, 1991, 2000 and 2010.

Tabela 2. Taxa de crescimento da urbanização do município de São Vicente/SP em cada período. Table 2. Growth rate of urbanized areas in the city of Sáo Vicente, State of São Paulo, at each period.

\begin{tabular}{lrrrrr}
\hline Período & \multicolumn{2}{c}{$\begin{array}{c}\text { Aumento da área } \\
\text { urbanizada (ha) }\end{array}$} & $\begin{array}{c}\text { Aumento da populaçáo } \\
\text { (habitantes) }\end{array}$ & $\begin{array}{c}\text { Variaçáo da área } \\
\text { urbanizada (\%) }\end{array}$ & $\begin{array}{c}\text { Aumento populacional } \\
\text { (\%) }\end{array}$ \\
\hline $1963-1972$ & 380 & 39.277 & 27,44 & 50,87 \\
\hline $1972-1987$ & 525 & 76.523 & 29,75 & 65,69 \\
\hline $1987-1994$ & 194 & 75.610 & 8,47 & 39,17 \\
\hline $1994-2001$ & 30 & 34.933 & 1,20 & 13,01 \\
\hline $2001-2007$ & 189 & 28.894 & 6,84 & 9,52 \\
\hline
\end{tabular}




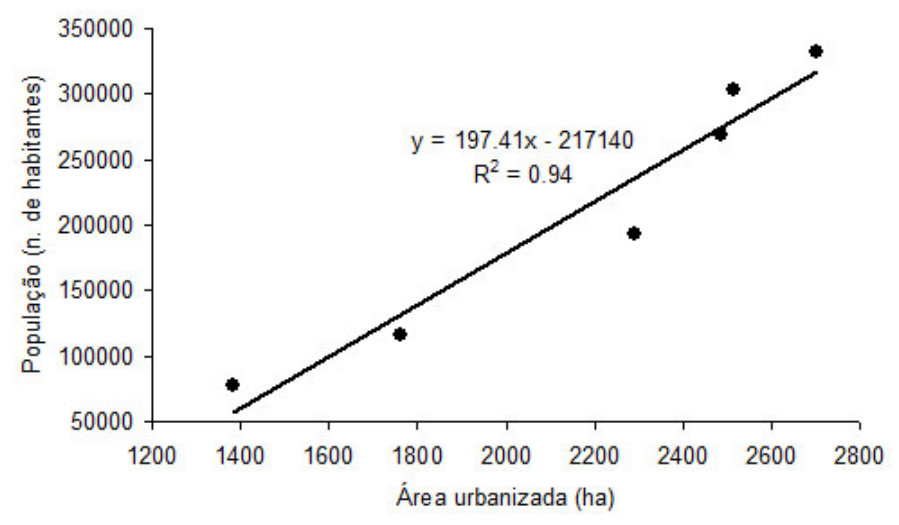

Figura 3. Regressão linear dos valores de área urbanizada e número de habitantes $\left(\mathrm{p}=0,0014 ; \mathrm{R}^{2}=0,94\right.$; correlação $\left.=88 \%\right)$.

Figure 3. Linear regression of the values of urbanized area and number of inhabitants $\left(p=0.0014, R^{2}=0.94\right.$, correlation $\left.=88 \%\right)$.
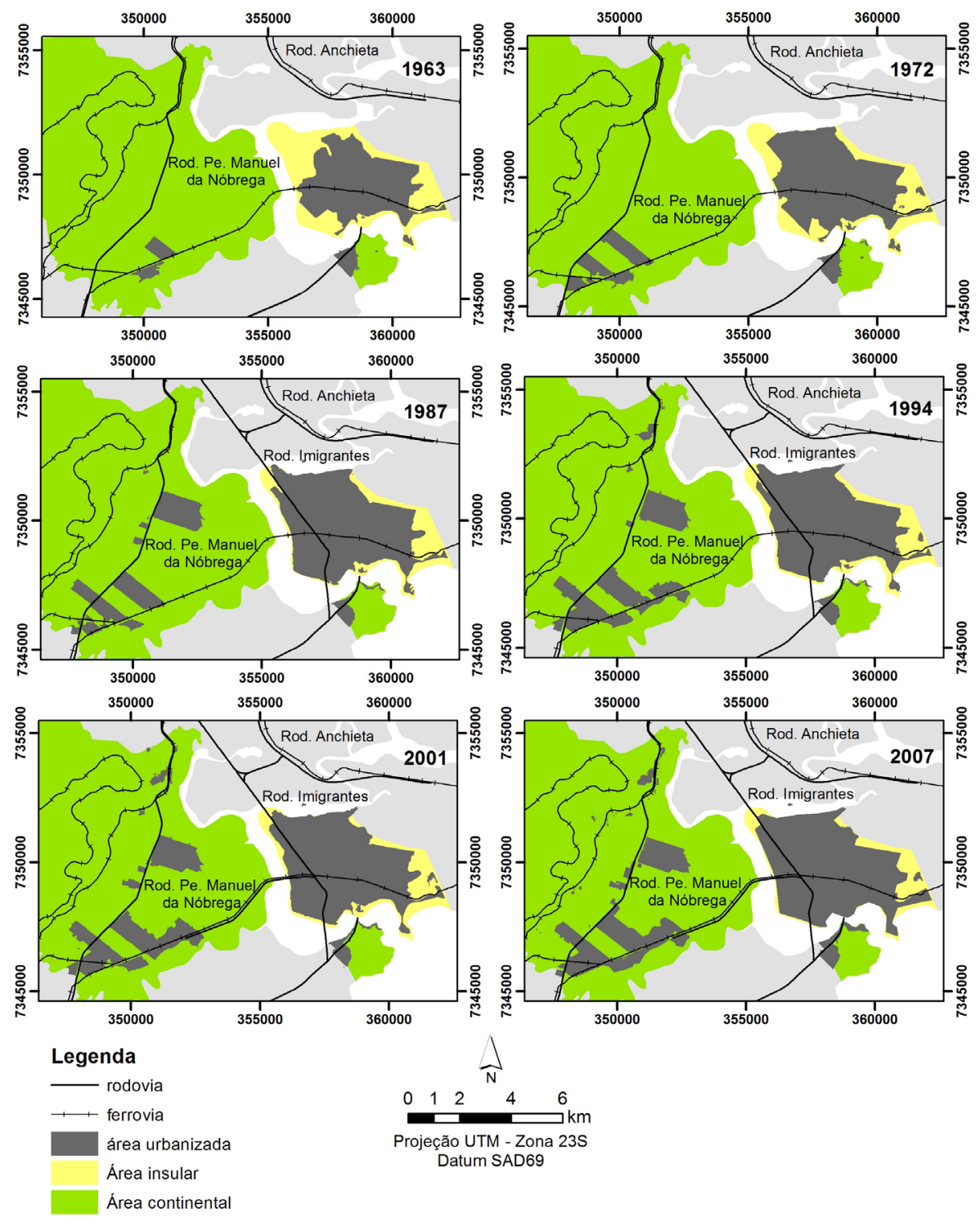

Figura 4. Expansão da mancha urbana no município de São Vicente entre os anos de 1963 e 2007. Figure 4. Expansion of urban area in the city of São Vicente between the years 1963 and 2007. 
Até a década de 1950, as atividades portuárias na RMBS constituíram a base para o crescimento urbano da região, associadas ao desenvolvimento da cidade de Sáo Paulo e do interior. Com solos pobres e trechos de alta declividade que não permitiam a expansão agrícola, o desenvolvimento teve um caráter urbano marcante para a Baixada Santista nessa época, com economia baseada no comércio. Com a inauguração da Refinaria Presidente Bernardes, em 1955, no município de Cubatão, juntamente com outras indústrias petroquímicas, foi estabelecida uma das mais importantes cadeias produtivas do país, iniciando-se uma importante fase para a economia regional, com o estabelecimento do polo industrial de Cubatão (Lisboa, 2005). A implantação do complexo industrial estimulou um processo migratório para a região, inclusive para o município de São Vicente, devido à oferta de trabalho, inicialmente na construçáo civil, e depois nas próprias indústrias (Ribeiro Neto \& Oliveira, 1989).

Nesse mesmo período, a planície litorânea era urbanizada junto ao mar, transformando dunas e restingas em um contínuo urbano linear. Essa urbanização foi associada ao intenso processo de parcelamento do solo e de construção de segundas residências, ligada à expansão da rede rodoviária estadual e à busca das praias para o lazer (Afonso, 2006). Devido à proximidade e à facilidade de transporte, a RMBS tornou-se o primeiro balneário de Sáo Paulo, e à medida que aumentava a população paulistana, aumentava também o fluxo de turistas para a regiāo (Ribeiro Neto \& Oliveira, 1989; Afonso, 2006). Esse cenário já era visível no ano de 1963, com a área insular do município de São Vicente bastante ocupada (Figura 4).

Grandes áreas foram loteadas para atender à demanda turística e de migrantes, além de obras de infraestrutura urbana. Entretanto, os empreendimentos não foram suficientes para atender ao grande número de migrantes que continuavam a chegar à regiāo, atraídos por oportunidades de trabalho nas décadas de 1960 e 1970 (Cunha et al., 2006). A fim de se atender ao grande fluxo de veículos para a região, pois a ligaçáo existente entre o litoral e o planalto (Rodovia Anchieta - SP 150) já não conseguia suportar o volume de veículos, foi construída a Rodovia dos Imigrantes (SP 160), inaugurada em 1976.

A construção da primeira pista da Rodovia dos Imigrantes, que facilitou o fluxo de veículos do planal to para a baixada, e, posteriormente, da Ponte do Mar Pequeno (1980), levaram a um grande crescimento da mancha urbana rumo ao litoral sul, devido à maior facilidade de acesso. $\mathrm{O}$ crescimento de Santos, Cubatão e Guarujá provocou um movimento em direção a outros municípios vizinhos, como São Vicente, que adquiriu características de cidade-dormitório. Nesse período observou-se a maior taxa de urbanização, alcançando quase $30 \%$ de crescimento (Tabela 2).

O maior aumento de áreas urbanizadas nesse período (1972-87) correlacionou-se intimamente ao aumento populacional do mesmo período (Tabela 2), que também apresentou o maior valor no período amostrado, com um crescimento de cerca de 76.000 habitantes. Esse aumento ocorreu, provavelmente, em função do crescimento econômico e industrial e da ampliação da demanda por bens e serviços, correlacionados com o incremento do turismo, e associados à inauguração da Rodovia dos Imigrantes. Nesse período, São Vicente adquiriu uma característica de receptor de moradores de baixa renda que se instalavam irregularmente às margens das rodovias dos Imigrantes e Padre Manoel da Nóbrega (SP 55) e ao longo do estuário (Afonso, 2006). O bairro "México 70", localizado em área aterrada do estuário na porção insular do município, foi uma das áreas que apresentou maior crescimento na porçấo insular (Figura 5), bem próximo à Rodovia dos Imigrantes recém-inaugurada. A valorização dos terrenos próximos à praia, os quais eram preferencialmente direcionados para uso como segunda residência, ea concentração de empreendimentos imobiliários dedicados a faixas mais abastadas na orla, fizeram com que a população de baixa renda fosse levada a ocupar as periferias, sobre manguezais, estuários ou nas encostas da serra (Afonso, 2006).

Na Figura 4, podemos observar que houve urbanização em áreas antes não ocupadas na área insular, próximas à nova rodovia, a partir do ano de 1987. Sendo assim, é notável a dependência da presença de vias de acesso para a expansão da mancha urbana na Baixada Santista, assim como em grande parte das regiōes tropicais (Teixeira et al., 2009; Cabral et al., 2007; Soares-Filho et al., 2004; Sader \& Joyce, 1988). O crescimento urbano em Santos, Cubatão e Guarujá, juntamente com a oferta de emprego nos setores de comércio e serviços, provocou um movimento "pendular" em direçáo a outros municípios, com espaço disponível e melhores condiçôes para construção de habitaçôes, como é o caso da área continental de São Vicente (Cunha et al., 2006).

A área continental, onde ainda existiam áreas para a expansão, possui uma taxa maior de crescimento de ocupação humana, com um crescimento de cerca de $480 \%$ para todo o período analisado, enquanto o crescimento da área insular foi de cerca de 47\% (Tabela 1). A população de baixa renda que não conseguia se fixar na região insular de Santos e São Vicente buscou assentamento nas áreas ambientalmente frágeis, como a área continental de São Vicente. Surgiu, entáo, a denominada "indústria" dos loteamentos clandestinos e irregulares, que resultou no loteamento sem autorização de grandes áreas (muitas delas sob proteção ambiental) que eram posteriormente vendidas para terceiros. O crescimento de assentamentos irregulares em São Vicente foi observado no aterramento de áreas de mangue e restinga e estabelecimentos de palafitas nos canais e estuários (Figura 5 e 6). Segundo Jakob et al. (2006), devido ao alto valor dos imóveis na área insular de São Vicente e à ausência de uma política habitacional que propiciasse financiamentos acessíveis, a oferta de terras baratas ou sem custo na área continental e nas áreas ambientalmente frágeis era a alternativa habitacional para a população de baixa renda.

As áreas ocupadas da região continental estão praticamente todas associadas à presença da rodovia Padre Manoel da Nóbrega (Figura 7), mostrando que o estabelecimento de rodovias representa um importante vetor de expansão urbana (Alves, 2002; Cunha-Lignon et al., 2009; Teixeira et al., 2009; Mello et al., 2012). Os bairros Humaitá, Parque Continental, Jardim Rio Branco, Glebas I e II e Vila Ema aparecem como manchas urbanas distribuídas ao longo da rodovia (Figura 7). Esses assentamentos foram responsáveis pela supressão de áreas de manguezal e restinga, que perfaziam a cobertura 


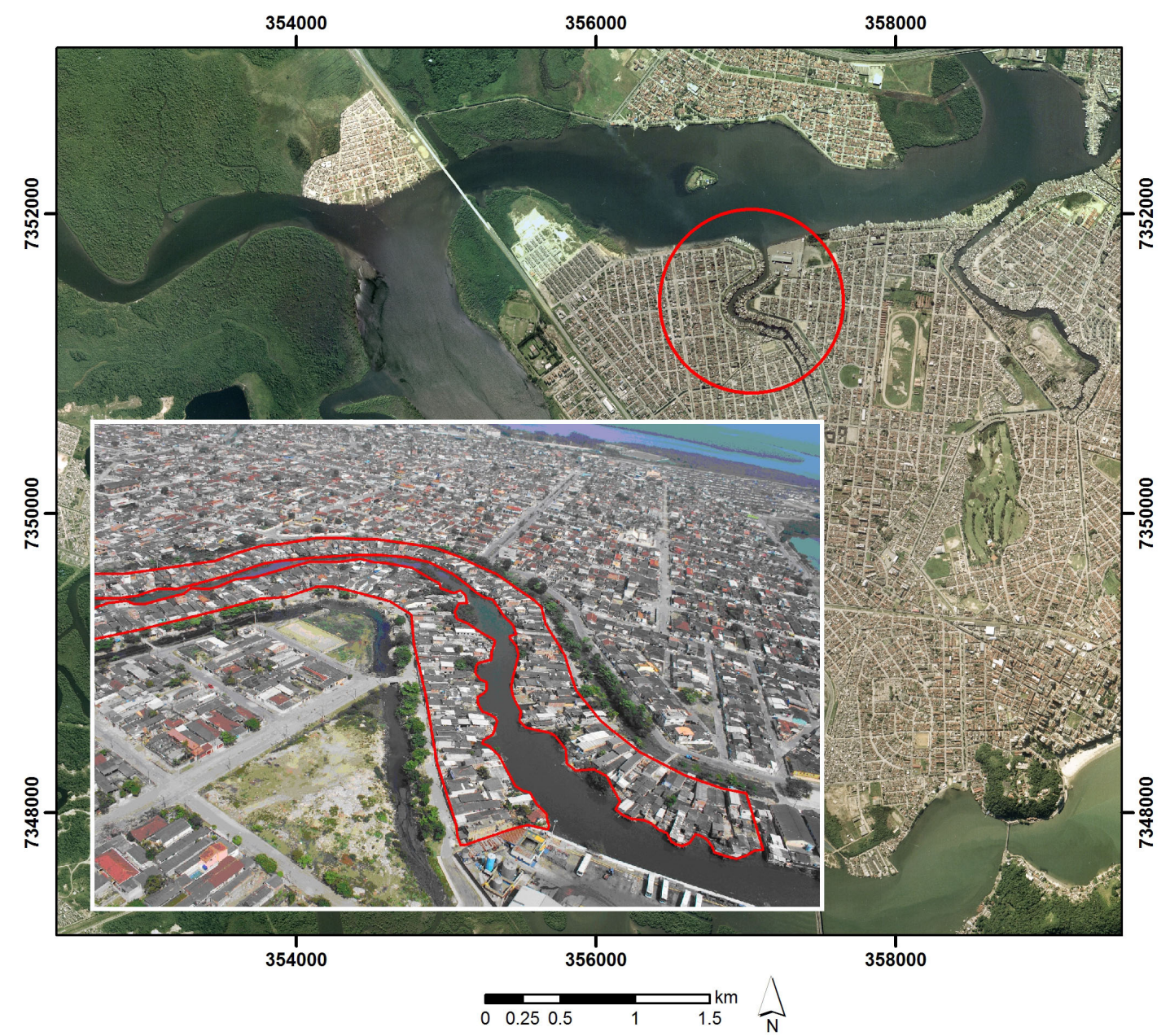

Figura 5. Ilha de São Vicente (Ortofoto do ano de 2001). Detalhe para palafitas associadas ao canal (Foto: TOPPA, R.H.; BUCHMAN, F.S., 2008).

Figure 5. São Vicente Island (Orthophoto of 2001). Detail for the "palafitas" slums in the channel banks (Photo: Toppa, RH; BUCHMAN, FS, 2008).

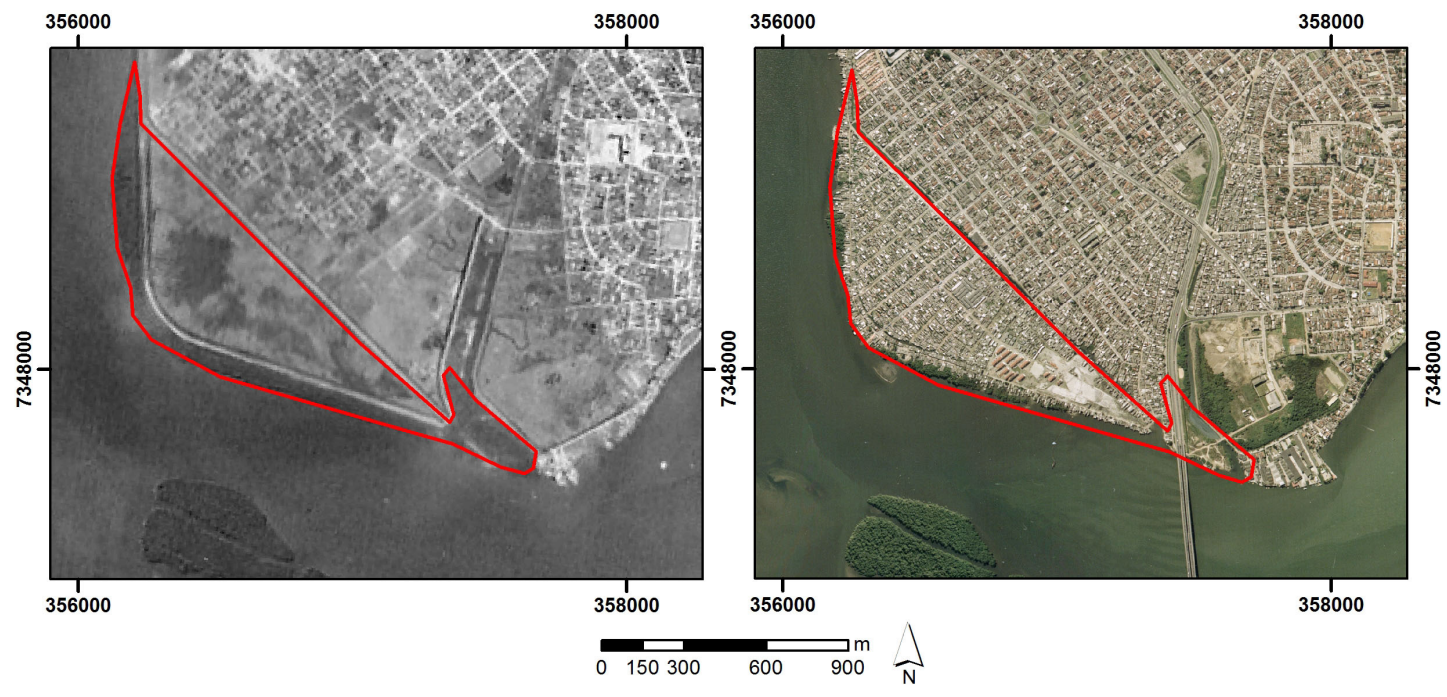

Figura 6. Localização do Bairro México 70 na Ilha de São Vicente, sem assentamentos urbanos sobre manguezais, em 1963 (à esquerda); e já integralmente consolidado em 2001 (à direita). Fonte: Fotografias aéreas dos anos de 1963 e 2001.

Figure 6. Location of Mexico 70 district, Säo Vicente Island, with no urban settlements on mangroves in 1963 (left) and in 2001, with fully consolidated occupation (right). Source: Aerial photographs of 1963 and 2001. 
vegetal original do local. Parte das ocupaçôes foi estabelecida sobre os aterros dos antigos lixóes contaminados por substâncias tóxicas da Rhodia (indústria de origem francesa fabricante de produtos químicos). Segundo Lamparelli et al. (2001), os depósitos de organoclorados da Rhodia, nos municípios de Cubatão e São Vicente, representam as áreas mais críticas de solo contaminado na Regiāo Metropolitana da Baixada Santista.

O período entre 1987 e 1994 coincidiu com sucessivas e graves crises econômicas no país e no mundo. O Brasil passou por um momento de estagnaçáo econômica, marcado pela hiperinflação, e somente no ano de 1994 a economia começou a melhorar, com a criação do Plano Real no Brasil, o qual estabilizou a moeda e permitiu a recuperação do poder de compra dos salários; com avanços no Governo Clinton na conduta de políticas econômicas nos EUA, e com o crescimento econômico da China, o que afetou positivamente toda a economia mundial. Esses grandes ciclos econômicos influenciaram nas atividades econômicas regionais, e podem estar diretamente correlacionados ao processo e à velocidade de ocupaçáo da RMBS, pois condicionaram os investimentos nos setores da regiáo, principalmente no setor portuário e industrial. A diminuição das taxas de crescimento da expansão urbana encontrada a partir desse período (Tabela 2) pode ser reflexo direto da crise econômica brasileira e mundial.

A diminuiçáo do ritmo de crescimento da urbanizaçáo no munícipio converge com as informaçóes do histórico demográfico, que mostram uma estabilização da taxa de crescimento da população nos últimos períodos (1994 a 2007). Além dos fatores econômicos, a diminuição do crescimento populacional e da mancha urbana pode estar correlacionada a mais três fatores: i) físicos, considerando a estreita faixa de terra da planície litorânea e o tipo de solo inadequado à ocupação, com áreas alagáveis e de manguezal, a ocupação passa a cobrir quase todas as áreas permitidas por lei para esse uso, restando apenas áreas protegidas; ii) espalhamento da especulação imobiliária rumo ao sul da Baixada Santista, em direção aos municípios de Mongaguá, Itanhaém e Peruíbe e rumo ao Litoral Norte do Estado, especialmente entre os municípios de Bertioga e São Sebastião, que oferecem maior atrativo pelo seu grau de conservaçáo dos ecossistemas naturais; iii) aumento da verticalização das moradias, que passa a ser mais acentuada em todos os municípios a partir desse período.

Cunha et al. (2006) também aponta o maior controle ambiental por parte do Estado a partir da década de 1980, que inibiu a expansão das atividades industriais químicas e petroquímicas na região. A partir dessa década, a questão ambiental se pronuncia com a criação do PESM, em 1977, abrangendo grande parte das vertentes da Serra do Mar no município de São Vicente, com a criação da Política Nacional de Meio Ambiente (Lei no 6.938/1981), do Plano Nacional de Gerenciamento Costeiro (Lei no 7.661/1988), com a criação do PEXJ, em 1993, que possui parte do seu território no município de São Vicente, e do Sistema Nacional de Unidades de Conservaçáo da Natureza (Lei no 9.985/2000). O bairro do Japuí, que faz divisa com o município de Praia Grande, localiza-se no entorno do PEXJ, e representa um fator de pressão à UC (Figura 8). Segundo o Instituto Florestal, $65 \%$ da vegetação do município são considerados como área

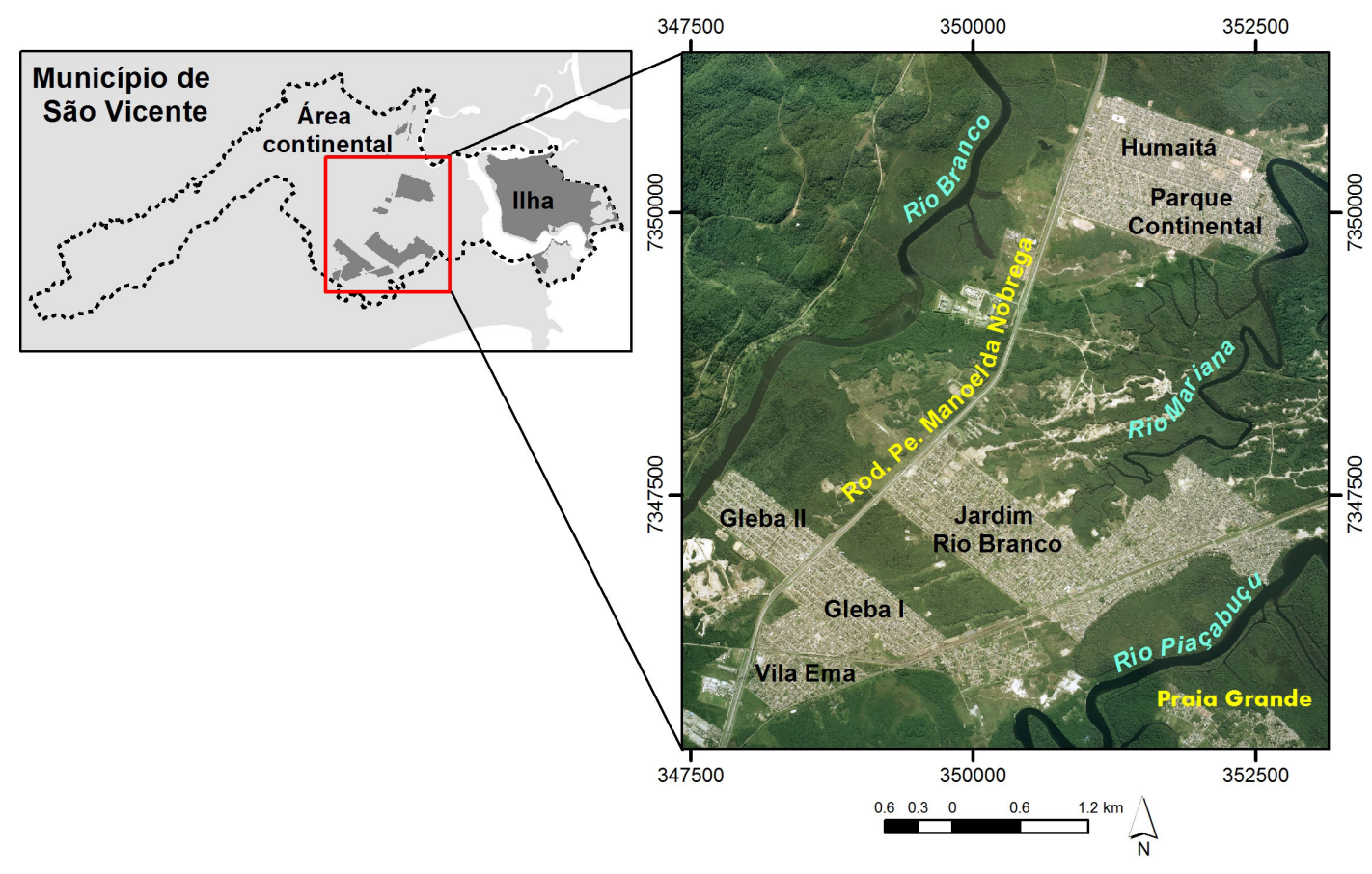

Figura 7. Urbanização na área continental de São Vicente, com identificação de alguns bairros. Fonte: Fotografia aérea de 2001.

Figure 7. Urbanization in the continental area of São Vicente, showing some identifiable districts. Source: Aerial photographs of 2001. 
preservada (SMA/IF, 2007), ilustrando a importância do planejamento do crescimento urbano municipal, de modo a dirimir os impactos negativos sobre as áreas preservadas.

Mesmo com a diminuição das taxas de crescimento populacional, o aumento da população continua, e, consequentemente, a expansão dasáreas urbanizadas. Segundo o IBGE (2011), a população da RMBS vem aumentando consideravelmente e apresenta "picos" nos meses de verão devido ao grande fluxo de turistas. A população flutuante em 2010 chegou a quase 60 mil habitantes no município de São Vicente, e um total de 1.350 .000 para toda a região, aumentando em quase duas vezes a população residente (1.625.000) (IBGE, 2011). Para Jakob (2004), a população flutuante de veraneio contribui para a verticalização e o aumento da periferia da RMBS, uma vez que necessita de infraestrutura e serviços em curtos períodos de tempo. Assim, a população flutuante potencializa os processos de verticalização $^{1}$ e de periferização ${ }^{2}$ na RMBS de uma forma geral. O aumento populacional gera excessiva demanda

1 - Crescimento de estruturas verticais na cidade, como construção de prédios.

2 - Ocupação de espaços distantes ao centro da cidade ou de bolsôes em meio à cidade, degradados ou sem infraestrutura, com habitaçóes precárias, caracterizados por população de baixa renda carente de serviços públicos e urbanos.

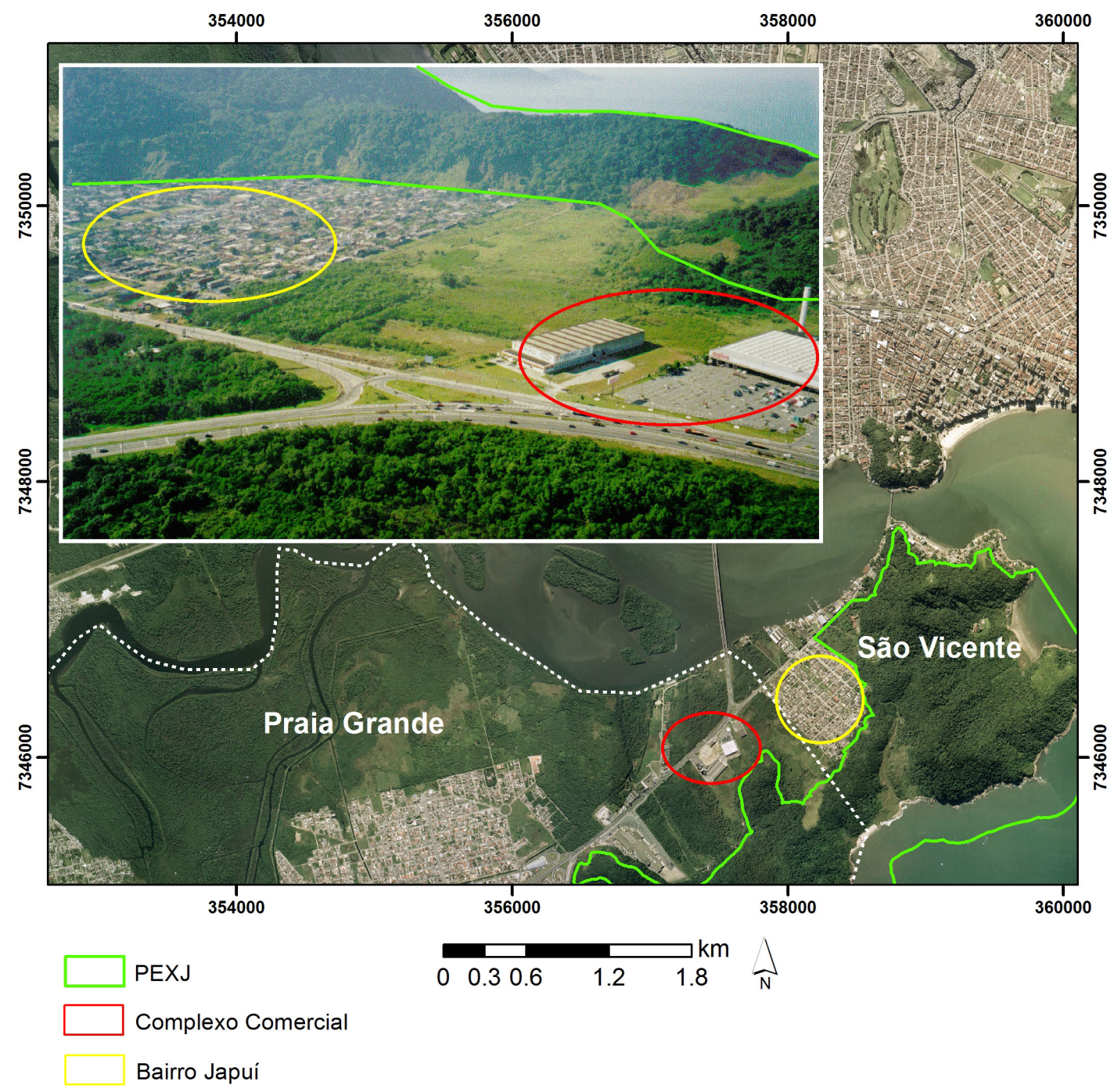

Figura 8. Divisa de São Vicente e Praia Grande (Fotografia aérea de 2001). Detalhe para o complexo comercial em Praia Grande, bairro Japuí em São Vicente e Parque Estadual Xixová-Japuí em ambos os municípios (Fotografia aérea cedida pela Coordenadoria de Planejamento Ambiental da Secretaria de Meio Ambiente do Estado de São Paulo - CPLA - SMA, 1999).

Figure 8. Border of the cities of São Vicente and Praia Grande (Aerial photographics of 2001). Detail for a shopping center in Praia Grande, the district of Japui at Säo Vicente and the Xixová-Japui State Park in both of cities (Aerial photograph provided by the Coordination of Environmental Planning from the Environmental State Secretary-CPLA-SMA, 1999). 
por serviços de infraestrutura urbana e, de fato, a economia da região está baseada na prestação de serviços e pouco na indústria (IBGE, 2011), com exceção dos municípios de Santos, Cubatão e Guarujá.

Em nenhum período foram observadas perdas de áreas urbanas ou conversão de área de um uso para o outro, indicando, assim, que não houve uma expressiva regeneração de vegetação na área de estudo para o período estudado. Mesmo com velocidades diferentes, como mostrado anteriormente, o crescimento de áreas urbanas foi permanente durante todos os anos. Esses dados traduzem a visão de desenvolvimento que existe na RMBS: um desenvolvimento não sustentável ligado à expansão de atividades econômicas e que não leva em consideração as implicaçóes ambientais e socioculturais. Os remanescentes de vegetação natural, grande parte protegidos por lei, cada vez mais sofrem com a pressão dos setores econômicos que buscam novas áreas para a expansão de suas atividades.

Nas últimas décadas, o crescimento da maioria dos municípios da RMBS apresentou taxas muito maiores do que o município de Santos, que é considerado a sede econômica dessa região, demandando deslocamentos cada vez mais intensos e extensos, causando diversos danos ambientais e exigindo vultosos investimentos em transportes. A previsão é de que ocorram novos fluxos migratórios para a RMBS até o ano de 2020, acrescentando pelo menos 25\% à população atual, os quais estarão intimamente relacionados à descoberta e exploração de jazidas de petróleo e gás na bacia de Santos e à ampliação do porto (SMA/CPLA, 2009). A chegada de empresas e de pessoas atraídas pela oferta de empregos acarretará em uma demanda muito grande por espaço. A área continental de São Vicente merece especial atenção quanto ao direcionamento dessa demanda, visto a tendência de crescimento das áreas urbanizadas ao longo das rodovias, encontrada nesse estudo, acompanhada pelo crescimento populacional, que foi de 26,1\% entre os anos de 2000 e 2010, contra um crescimento de apenas 4\% da populaçáo insular (IBGE, 2011).

Há, dessa forma, uma necessidade de planejamento da expansão urbana e de criação de políticas públicas que garantam a proteçáo dos ambientes costeiros frente a esse cenário de crescimento econômico da Baixada Santista, que ameaça esses ambientes frágeis e táo importantes, tanto ecologicamente como economicamente. O planejamento deve ser feito de forma regional, e não municipal, envolvendo critérios para ocupação urbana e gerenciamento das Unidades de Conservação, visando à conservação dos bens e serviços ambientais, bem como das áreas frágeis e ecologicamente relevantes. A melhoria da mobilidade urbana regional e dos serviços públicos municipais, a potencializaçáo do uso de espaços urbanos ociosos ou subutilizados, programas habitacionais e a revitalização de espaços públicos poderia reduzir a pressão sobre as UC, evitando-se a expansão de loteamentos em direção a essas áreas. Recentemente aprovado, o Zoneamento Ecológico Econômico da Baixada Santista (Decreto no 58.996/2013) visa estabelecer o planejamento ambiental, assim como os planos de manejo das UC (PEXJ e PESM) e o Plano de Bacia Hidrográfica da Baixada Santista. Porém, é importante que esses instrumentos sejam alinhados e que não fiquem apenas no papel, mas resultem em açóes e políticas públicas apropriadas, e que sejam utilizados pelos municípios no estabelecimento dos Planos Diretores e direcionamento da expansão urbana.

O planejamento territorial do município de São Vicente deve considerar a disponibilidade de áreas para a população de baixa renda, conciliando programas habitacionais e de saneamento básico a programas de recuperação ambiental, principalmente de áreas de manguezal, restinga e Mata Atlântica. As políticas de expansão urbana devem ser compatíveis às restrições ambientais das zonas de amortecimento das Unidades de Conservação e, ainda, garantir locais adequados de moradias para se atender às necessidades de habitação da população, evitando-se conflitos tanto ambientais como sociais em áreas frágeis e de risco.

\section{CONCLUSÓES}

Desde 1963, já havia um núcleo urbano consolidado em São Vicente, associado à mancha urbana localizada na ilha e, na parte continental, correlacionada ao bairro do Japuí. Porém, a expansão desses núcleos urbanos, principalmente nas áreas associadas à ilha de São Vicente, se correlaciona ao processo de favelização.

No período abrangido por este estudo, a expansão urbana ocorreu na parte continental do município, sobre territórios onde havia vegetação natural, porém, fica evidente que as estradas e a ferrovia atuaram como vetores para essa ocupação e para o adensamento urbano.

O pico de crescimento de $29,75 \%$ no período de $1972-$ 1987 se correlaciona com um aporte estrutural na região, em especial a expansão das rodovias que ligam a capital do estado com a RMBS (e, secundariamente, as vias conectando os municípios costeiros entre si), fortalecendo um turismo de massa regional, e influenciando na migração de pessoas, que se fixaram principalmente em São Vicente, que adquiriu a característica de cidade dormitório.

$\mathrm{O}$ ordenamento territorial deve respeitar os diferentes instrumentos políticos que podem interferir no uso e na ocupação de terras de forma a atuarem positivamente para a sustentabilidade regional, como, por exemplo, as Unidades de Conservação de proteção integral existentes. Esse ordenamento deve estar articulado ao planejamento costeiro regional para cumprir as demandas voltadas à gestão integrada para a tomada de decisão nas dimensôes econômica, sociocultural, ambiental e política.

Com base nos resultados observados, podemos considerar que a dinâmica da paisagem na área de estudo é refém dos ciclos econômicos, porém, nos permitiu estabelecer uma análise de tendências associadas ao crescimento urbano regional, que se mostra de forma pouco ordenada. Esse fato pode ser agravado frente ao início de um novo período econômico associado à exploração de óleo e gás na Bacia de Santos, o que poderá gerar ainda mais o adensamento urbano para São Vicente, assim como para os demais municípios da RMBS. Deve-se ressaltar que os únicos locais para a expansão das cidades, nessa região, estão associados, em sua maioria, aos remanescentes de Mata Atlântica. Assim, com base no processo histórico de ocupação identificado, pode-se inferir que a tendência regional indica uma drástica substituição da paisagem natural ainda existente em áreas limítrofes às 
Unidades de Conservação, por uma paisagem antrópica, que provavelmente será representada por ocupaçóes irregulares sem infraestrutura urbana adequada para a sustentabilidade regional.

\section{REFERÊNCIAS BIBLIOGRÁFICAS}

Afonso, C.M. (2006) - A paisagem da Baixada Santista: Urbanização, transformação e conservação. 309p., Edusp/ FAPESP, São Paulo, SP, Brasil. ISBN: 8531408938.

Afonso, C.M. (2005) - Transformação ambiental e paisagística na Baixada Santista, SP. Paisagem e Ambiente (ISSN: 01046098), 20:85-130, USP - Universidade de São Paulo, São Paulo, SP, Brasil. Disponível em http://www.revistas.usp. $\mathrm{br} / \mathrm{paam} /$ article/view/40231/43097

Alves, D.S. (2002) - An analysis of the geographical patterns of deforestation in Brazilian Amazonia in the 1991-1996 period. In: Charles H. Wood \& Roberto Porro (eds.), Land Use and Deforestation in the Amazon, pp. 95-106, University Press of Florida, in press, Gainesville, Florida, EUA. ISBN: 0-8130-2464-1.

Amorim, R.R.; Oliveira, R.C. (2008) - As unidades de paisagem como uma categoria de análise geográfica: o exemplo do município de São Vicente-SP. Sociedade \& Natureza, 20(2):177-198. DOI: 10.1590/S198245132008000200011

Cabral, D.C.; Freitas, S.R.; Fiszon, J.T. (2007) - Combining sensors in landscape ecology: imagery-based and farmlevel analysis in the study of human-driven forest fragmentation. Sociedade \& Natureza (ISSN 1982-4513), 19:69-87, UFU - Universidade Federal de Uberlândia, Uberlândia, MG, Brasil.

Cunha, J.M.P.; Jakob, A.A.E.; Young, A.F. (2006) Dinâmica Demográfica Intrametropolitana na Região Metropolitana da Baixada Santista no período pós-1970. In: Cunha, J.M.P. (Org.), Novas Metrópoles Paulistas - populaçáo, vulnerabilidade e segregaçáo, pp.399-434, Núcleo de Estudos da População, Unicamp - Universidade Estadual de Campinas, Campinas, SP, Brasil. ISBN: 9788588258082. Disponível em http://www.nepo.unicamp. $\mathrm{br} /$ textos/publicacoes/livros/vulnerabilidade/arquuivos/ arquuivos/vulnerab_cap_14_pgs_399_434.pdf

Cunha-Lignon, M.; Menghini, R.P.; Santos, L.C.M.; Niemeyer-Dinóla, C.; Schaeffer-Novelli, Y. (2009) Estudos de Caso nos Manguezais do Estado de São Paulo (Brasil): Aplicação de Ferramentas com Diferentes Escalas Espaço-temporais. Revista da Gestão Costeira Integrada, 9(1):79-91. DOI: $10.5894 / \mathrm{rgci} 125$

Dahdouh-Guebas, F. (2002) - The use of remote sensing and GIS in the sustainable management of tropical coastal ecosystems. Environment, Development and Sustainability, 4:93-112. DOI: $10.1007 / s 10668-006-9049-0$

IBGE (2011) - Sinopse do Censo Demográfico 2010. 261p., IBGE - Instituto Brasileiro de Geografia e Estatística, Rio de Janeiro, RJ, Brasil. ISBN: 978-8524041877. Disponível em: http://www.ibge.gov.br/home/estatistica/ populacao/censo2010/sinopse.pdf?

Jakob, A.A.E. (2004) - Análise sócio-demográfica da constituição do espaço urbano da região metropolitana da Baixada Santista no periodo de 1960-2000. Campinas, São
Paulo, Brasil. 134p., Textos Nepo (ISSN: 1413-9243) no 45, Núcleo de Estudos de População, Universidade Estadual de Campinas, Campinas, SP, Brasil. Disponível em http://www.nepo.unicamp.br/textos/publicacoes/ textos_nepo/textos_nepo_45.pdf

Jakob, A.A.E.; Cunha, J.M.P.; Young, A.F. (2006) - Riqueza a beira-mar, pobreza longe da maresia: um retrato da segregaçáo social na Região Metropolitana da Baixada Santista, nos anos 1990. In: Cunha, J.M.P. (Org.), Novas Metrópoles Paulistas - população, vulnerabilidade e segregação, pp. 435-455, Núcleo de Estudos da População, Unicamp - Universidade Estadual de Campinas, Campinas, SP, Brasil. ISBN: 978-8588258082. Disponível em http:/www.nepo.unicamp.br/textos/ publicacoes/livros/vulnerabilidade/arquuivos/arquuivos/ vulnerab_cap_15_pgs_435_455.pdf

Lambin, E.F. (1997) - Modeling and monitoring land-cover change processes in tropical regions. Progress in Physical Geography, 21(3):375-393. DOI: 10.1177/030913339702100303

Lamparelli, M.L.; Costa, M.P.; Prósperi, V.A.; Bevilácqua, J.E.; Araújo, R.P.A.; Eysink, G.G.L.; Pompéia, S. (2001) Sistema Estuarino de Santos e São Vicente. 178p., CETESB - Companhia de Tecnologia de Saneamento Ambiental, São Paulo. SP, Brasil. Disponível em http://www.acpo.org. br/biblioteca/06_areas_contaminadas_\%20saturadas/ relatorio_sistema_estuarino_santos_sv.pdf

Lisboa, M.A.L. (2005) - Cubatão. 192p., Ed. Beca, São Paulo, SP, Brasil. ISBN: 8587256467.

Mello, K.; Abessa, D. M. S.; Toppa, R. H. (2012) - Influência de rodovias no processo de transformação da paisagem: o caso do Sistema Anchieta-Imigrantes. In: Bager, A. (Org.), Ecologia de Estradas: Tendências e Pesquisas, pp.267-282, UFLA - Universidade Federal de Lavras, Caxambu, MG, Brasil. ISBN: 978-8581270067.

Ribeiro Neto, F. B.; Oliveira, M. F. (1989) - Estratégias de sobrevivência de comunidades litorâneas em regióes ecologicamente degradadas: o caso da Baixada Santista. 132p., Programa de Pesquisa e Conservação de Áreas Úmidas no Brasil/Fundação Ford/UICN/IO-USP, São Paulo, SP, Brasil. Disponível em http://nupaub.fflch.usp. br/sites/nupaub.fflch.usp.br/files/color/santos.pdf

SMA/CPLA (2009) - Projeto Ambiental Estratégico Cenários Ambientais 2020. 150p., SMA - Secretaria do Meio Ambiente / CPLA - Coordenadoria de Planejamento Ambiental, São Paulo, SP, Brasil. ISBN: 978-8586624629. Disponível em http://200.144.189.97/phd/LeArq. aspx?id_arq $=4305$

SMA/IF (2007) - Inventário Florestal da vegetação natural do Estado de São Paulo: Regióes Administrativas de São José dos Campos (Litoral), Baixada Santista e Registro. 140p., SMA - Secretaria do Meio Ambiente / IF - Instituto Florestal - Imprensa Oficial do Estado de São Paulo, São Paulo, SP, Brasil. Disponível em http://www.iflorestal.sp.gov.br/ sifesp/ifVegnaturalsp_\%20litoral.zip

Sader, S.A.; Joyce, A.T. (1988) - Deforestation rates and trends in Costa Rica, 1940-1983. Biotropica, 20(1):1119. DOI: $10.2307 / 2388421$

Soares-Filho, B.S.; Alencar, A.; Nepstad, D.; Cerqueira, G.; Diaz, M.D.C.V.; Riveiro, S.; Solorzano, L.; Voll, 
E. (2004) - Simulating the response of land-cover changes to road paving and governance along a major Amazon highway: the Santarém-Cuiabá corridor. Global Change Biology, 10(5):745-764. DOI: 10.1111/j.15298817.2003.00769.x

Teixeira, A.M.G.; Soares-Filho, B.S.; Freitas, S.R.; Metzger, J.P. (2009) - Modeling landscape dynamics in an Atlantic Rainforest region: Implications for conservation. Forest Ecology and Management, 257(4):1219-1230. DOI: 10.1016/j.foreco.2008.10.011

Toppa, R.H.T.; Mello, K.; Moraes, M.C.P. (2013) - Planejamento de Unidades de Conservaçáo e geotecnologias: aspectos históricos e aplicaçôes técnicas. In: Piratelli, A.J.; Francisco, M.R. (Orgs.), Conservação da Biodiversidade: dos conceitos às açôes, pp.195-216, Technical Books, Rio de Janeiro, RJ, Brasil. ISBN: 97885-61368-36-4.

\section{LEGISLAÇÃO REFERIDA}

Decreto no 58.996, de 25 de março de 2013. Dispóe sobre o Zoneamento Ecológico-Econômico do Setor da Baixada Santista e dá providências correlatas. Disponível em http://www.ambiente.sp.gov.br/cpla/files/2011/05/ DECRETO-No-58996-DOE.pdf
Lei $\mathrm{n}^{\circ} 7.661$, de 16 de maio de 1988. Institui o Plano Nacional de Gerenciamento Costeiro e dá outras providências. Publicado no D.O.U. de 18.5.1998. Disponível em http://www.planalto.gov.br/ccivil_03/Leis/L7661.htm

Lei $n^{\circ} 6.938$, de 31 de agosto de 1981. Dispóe sobre a Política Nacional do Meio Ambiente, seus fins e mecanismos de formulação e aplicação, e dá outras providências. Publicado no DOU de 2.9.1981. Disponível em http:// www.planalto.gov.br/ccivil_03/Leis/L6938.htm

Lei ${ }^{\circ}$ 9.985, de 18 de julho de 2000. Institui o Sistema Nacional de Unidades de Conservaçấo da Natureza e dá outras providências. Publicado no D.O.U. de 19.7.2000. Disponível em http://www.planalto.gov.br/ccivil_03/ Leis/L9985.htm 